all. The medical reader, too, will find little that is faulty or deficient in Miss Sturge's account and explanation of the "healing" side of Christian Science. What Mark Twain's admirable and irresistible articles in the North Amerioan Review do for the average man and woman of the world in the way of showing the real nature of Christian Soience, its grossly material side and its commingled spiritual excellences, that Miss Sturge's book will do for the thoughtful reader and the student of religion, if only such persons can endure the ordeal of reading a just account of Christian Science.

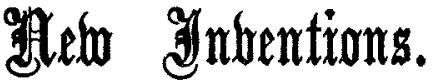

\section{IMPROVEMENTS IN VAGINAL TUBES.}

IN The LaNceT of Dec. 4th, 1897, p. 1463, I described a new form of vaginal tube the chief characteristics of which were a bulbous end and a comparatively thin rigid shaft. This scientifically adjusted and practicable instrument offered the one disadvantage of the bulb being hollow. It has hitherto been considered by gynæcologists and obstetricians that all vaginal tubes must of necessity have a number of perforations terminating into the central canal. The common red gum-elastic tubes, used hygienically by women, as well as all glass tubes used by surgeons, have been made in this way. A tube with several very small perforations, however, cannot easily be kept clean. I have found that, provided a tube be bulbous, as seen in Fig. 1, only one bore is necessary, running from end to end, particularly if this bore enlarges at its extreme end, as seen in Fig. 2 (section); the bulb dilates every part of the vagina and its
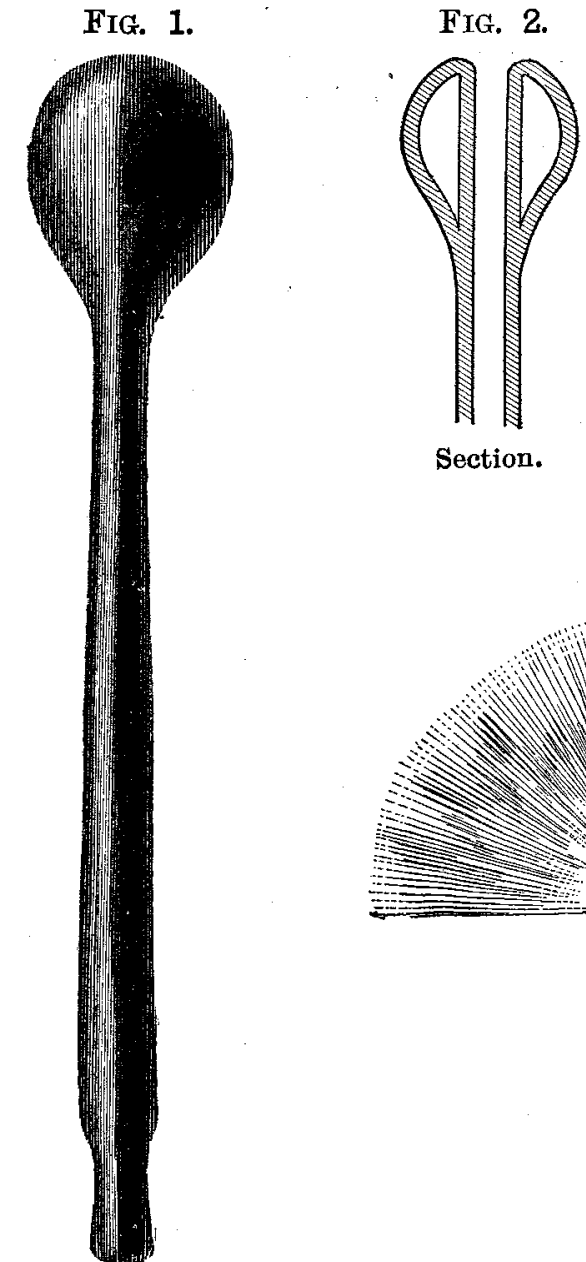

FIG. 3.

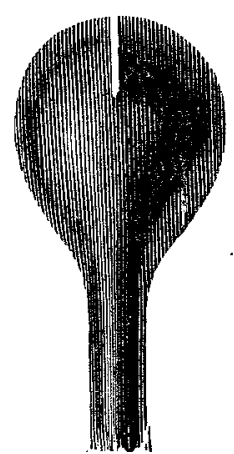

FIG. 4.

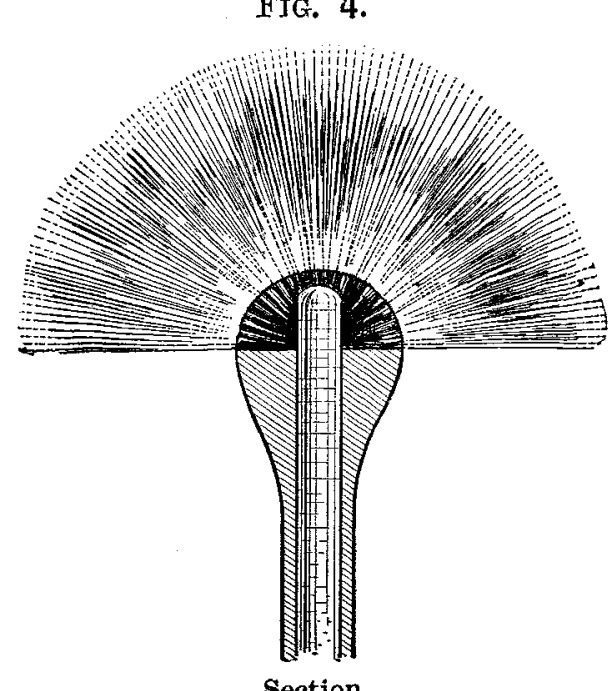

fornices, according as it is manipulated and levered, while the fluid distributes itself just as widely, practically, as it would when passing through a number of perforations. This simply-constructed bulbous tube in glass or vulcanite is thus the easiest possible to keep clean; it may be antisepticised more readily and perfectly than any other vaginal tube in existence. In the case of glass the bulb is not solid between the bore and the circumference, but hollow, as seen in Fig. 2 (section), and there is no communication between the bore and the cavity of the bulb. Experiment shows that a tube having a solid-walled bulb could not be made in either glass or earthenware, and if it could be made it would not lend itself for fine manipulation as does a hollow lighter one. The glass bulb illustrated also floats in fluid and may be dropped into a vessel containing fluid without breaking.

Another vulcanite form of tube, Fig. 3 and Fig. 4 (section), has its single bore met near the end by a very narrow bisecting slot, which not only spreads the fluid, as seen in Fig. 4 but prevents the tube from being blocked by clot or other material returning in a back flow, as the perforations of tubes commonly used frequently are. This form of tube may be preferred by those who use a Higginson's syringe. The small end of each tube is made to fit any ordinary indiarubber douche or syringe tubing.

The glass tubes are made in one design, as illustrated in Fig. 2, and with one size of bulb only, namely one and a quarter inches in diameter. In vulcanite the bulbs are of two sizes, one and three-eighths and one and one-eighth inches respectively in diameter, and have two distinct designs, the one having a single bore and the other a single bore met by a slot. They are supplied by W. H. Bailey and Son, 38, Oxford-street, London, W.

Surbiton.

HAYDN BROWN.

\section{ROYAL COLLEGE OF PHYSICIANS OF LONDON.}

A Comitia was held on Feb, 19th, Sir William Selby Church, Bart., K.C.B., the President, being in the chair. The meeting had been adjourned from Jan. 29th.

A report was received from the Laboratories Committee, dated Dec 5th, 1902. On the motion of the Senior Censor (Sir R. Douglas Powell), seconded by the Second Censor (Dr. G. Vivian Poore) the report was received and adopted.

The Harveian librarian (Dr. J. F. Payne) presented a list of books and other publications which had been given to the library during the past quarter and the thanks of the College were ordered to be given to the donors.

The annual return by the examiners of the results of the examination for the Licence in the year 1902 was received and ordered to be entered on the minutes.

The PrEsident then dissolved the Comitia.

Annual Dinner of the West London MedicoChiRURGical Societr. - The members and friends of the West London Medico-Chirurgical Society held the twentyfirst annual dinner of the society at the Trocadéro Restaurant, London, on Feb. 19th, under the chairmanship of the President of the society, Mr. Rickard W. Lloyd. The first toast after the customary loyal toasts was "The Imperial Forces," proposed by Mr. T. R. Atkinson who in the course of his remarks on the medical department of the army pointed out that the institution of the Medical Staff College in the metropolis was a great sign of the times. Sir William Taylor, K.C.B. (Director-General of the Army Medical Service), in reply, referred to the services rendered by the West London Medico.Chirurgical Society and similar associations in the cause of the wives and children of those who were obliged to go on active service. He looked forward to the time when the civil members of the medical profession would know more of the medical department of the army and he trusted that the establishment of the Medical Staff College in London would prove that its members were not unworthy of the consideration of their brethren. The toast of the "We: $t$ London MedicoChirurgical Suciety" was given by Mr. F. Swinford Edwards and acknowledged by the President. Mr. C. R. B. Keetley followed with a witty speech in which he proposed "The Kindred Societies." Mr. Howard Marsh, who replied in his official capacity as the President of the Clinical Society of London, received hearty applause for a spirited and humorous answer to Mr. Keetlev's good-natured raillery. Dr. Seymour Taylor proposed "The Guests," for whom Dr. J. F. W. Silk answered. After Mr. Lloyd had acknowledged the toast of "The President," proposed by Dr. F. F Schacht, the officers of the society, Mr. T. Gunton Alderton (treasurer), Dr. E. A. Saunders (senior secretary), Mr. H. P. Dunn (editor of the society's journal), and Mr. W. McAdam Eccles (editorial secretary), duly acknowledged the compliment paid to them by Mr. Alban H. G. Doran. 